\title{
OBJEÇÕES DE MICHAEL SANDEL À CONCEPÇÃO MORAL DE PESSOA NA TEORIA DA JUSTIÇA DE JOHN RAWLS
}

\author{
Ubiratan Trindade \\ Universidade do Vale do Rio dos Sinos - Unisinos - Brasil
}

\section{Resumo}

Neste artigo, vou analisar as críticas endereçadas a John Rawls, mais exatamente à concepção moral de pessoa que se encontra situada na posição original, um artifício de representação criado pelo filósofo americano, em sua obra A Theory of Justice de 1971. A posição original é um procedimento figurativo, o mesmo que o contrato para as teorias contratualistas, o que permite a seus participantes, representar os interesses de cada um, de maneira equitativa, resultando então, que as decisões tomadas, terão consequências equitativas.

Palavras-chave: Teoria da justiça, posição original, concepção de pessoa.

\section{Situando o problema}

A teoria da justiça como equidade tornou-se conhecida em 1971, quando John Rawls publicou sua influente obra, A Theory of Justice, estabelecendo um novo patamar, para o debate e a reflexão na filosofia política. O surgimento de A Theory of Justice foi saudada por apoiadores e até mesmo seus críticos, por ter vindo fechar uma lacuna existente na filosofia política. Sua obra, sua teoria e seu pensamento, fazem de John Rawls um dos mais influentes filósofos contemporâneos, contribuindo substancialmente para aqueles que pensam e refletem a sociedade atual.

A obra de Rawls pode ser lida, como oferecendo um ponto de confluência de duas grandes tendências do pensamento político ocidental: de um lado o compromisso com a construção de uma sociedade justa e, de outro, com a preservação das liberdades individuais. A Theory of Justice (1971) contém tanto um forte compromisso com os direitos individuais quanto um argumento robusto em favor da justiça socioeconômica a partir de uma só teoria filosófica coerente. Conforme Rawls "cada pessoa possui uma inviolabilidade fundada na justiça que nem mesmo o bem-estar da sociedade como um todo pode ignorar" (1971, p. 3). 
São exatamente essas instituições sociais e as pessoas envolvidas na elaboração das políticas públicas, tomando decisões no campo da cooperação ou da punição, que estão sendo avaliadas por Rawls e sua teoria. Para ele, a avaliação de tais práticas e regras que estão sob o domínio de pessoas morais, é do domínio da justiça social. Assim, a avaliação moral de agentes individuais ou coletivos e o resultado de suas condutas dentro de algum esquema institucional existente é predominantemente o domínio da ética. Conforme Thomas Pogge (2007, p. 29), “esses dois domínios, o da moral e o da ética, não são independentes”. Assim, as instituições sociais de uma sociedade têm influência substancial sobre as opções disponíveis para seus membros e até mesmo na formação dos mesmos.

A articulação de uma teoria política com bases morais, centrada no compromisso com o justo, defendida por Rawls, foi levada a cabo a partir de duas ideias centrais: (a) como um sistema de cooperação de beneficio mútuo; (b) como uma estrutura básica da sociedade que estabelece os principais termos de cooperação. O problema da teoria da justiça como equidade foi, então, estipular uma teoria da justiça social formulada nos termos da cooperação, levando em conta a estrutura básica da sociedade e proporcionando a virtude da justiça. De acordo com Rawls,

Para nós, o objeto primário da justiça é a estrutura básica da sociedade, ou mais exatamente, a maneira pela qual as instituições sociais mais importantes distribuem direitos e deveres fundamentais e determinam a divisão de vantagens provenientes da cooperação social (RAWLS, 1971, p. 7).

Resta então, que a teoria da justiça como equidade sustenta que a estrutura básica mais justa de uma sociedade é aquela que alguém escolheria se não soubesse qual viria a ser seu papel particular no sistema de cooperação social.

A estrutura básica da sociedade permite desigualdades econômicas e organizacionais, desde que essas desigualdades melhorem a situação de todos, especialmente a situação dos menos privilegiados. Assim, a teoria da justiça de Rawls pode ser vista como uma teoria ética neocontratualista que busca a justificação pública dos princípios políticos, afirmando a objetividade desses princípios a partir de sua aceitabilidade. Sua estratégia de justificação está em assegurar que fatos sociais, tais quais instituições políticas e econômicas justas, são produto de um processo de construção, em que os agentes racionais, estabelecem um acordo sobre os princípios para regular suas relações, identificando a estrutura básica da sociedade como objeto primeiro da justiça como equidade.

\section{A Theory of Justice e seus críticos}


A despeito da grandeza de sua obra, Rawls sofreu duras críticas procedentes principalmente de pensadores defensores das correntes libertárias e comunitaristas. Libertarianos como Nozick (1974), sustentam que Rawls e sua teoria dão um valor muito grande ao papel do Estado. Como sabemos, Nozick é um teórico adepto do Estado mínimo e defende que quanto menos o Estado estiver presente em nossas vidas, mais temos liberdade para desenvolver nosso gênio egoísta. Por outro lado, representantes da chamada corrente "comunitarista" como, por exemplo, Charles Taylor e Michael Sandel, Michael Walzer e Alasdair MacIntyre interpretaram "a teoria da justiça como equidade como deontológica, procedimental, universalista (abstrata) e que estabelece a prioridade do justo sobre o bem" (SILVEIRA, 2008, p. 122).

Na concepção dos comunitaristas, que sustentam a precedência da comunidade com relação ao indivíduo, modelos liberais como o de Rawls tendem a conceber um indivíduo isolado da comunidade e de suas ideias correlatas de bem- comum. Ainda, possibilitam o afastamento do indivíduo de sua tradição e contexto, tornando-o incapaz de assegurar a coesão e integração a um determinado grupo social. Essas críticas comunitaristas estão situadas no debate liberalismo-comunitarismo (the liberal-communitarian debate) ambientados nos anos oitenta do século passado. Surgiu exatamente após a publicação de $A$ Theory of Justice, que proporcionou um novo modelo de teoria da justiça para a filosofia política.

As críticas de Taylor, ao conceito de pessoa elaborado por pensadores liberais como Rawls podem ser vistas na obra Argumentos Filosóficos ${ }^{1}$ e, no artigo Atomism $^{2}$, publicado em 1992. Taylor examina a questão do atomismo em teorias políticas e sociais, descrevendo o termo como uma característica das teorias de contrato social e outras cuja pressuposição básica é a visão da sociedade constituída por indivíduos para o cumprimento de fins tendo como objetivo primeiro seus próprios planos de vida boa. Para nosso propósito, no entanto, vamos nos ater mais precisamente às críticas de Sandel à partir de sua obra Liberalism and the Limits of Justice ${ }^{3}$, quando o mesmo desafia a teoria de Rawls, pondo à prova a questão da justiça ter prioridade sobre o bem ou, se quisermos, nas palavras do próprio Rawls, quando afirma que a justiça é a primeira virtude de todas as coisas. Vamos analisar as objeções de Sandel e tentar argumentar que o conceito de pessoa, tal como proposto por Rawls, em $A$

\footnotetext{
${ }^{1}$ TAYLOR, Charles. Argumentos filosóficos. São Paulo: Edições Loyola, 2000. Propósitos entrelaçados: o debate liberal-comunitário, p. p. 197-220.

${ }^{2}$ Atomism In: AVINERI, Shlomo e DE-SHALIT Avner. Communitarianism and individualism. New York: Oxford University Press, 1992, p. 29-50.

${ }^{3}$ SANDEL, Michael. Liberalism and the Limits of Justice. Cambridge: Cambridge University Press, 1982.
} 
Theory of Justice é coerente com a politica e o modelo das sociedades democráticas contemporâneas.

De acordo com Sandel (1982, p. 28), do ponto de vista de uma intepretação empirista a posição original, não consegue sustentar um argumento deontológico. E para confirmar sua tese, procede a um exame das condições que caracterizam a posição original tal como Rawls a descreve. Para fazer tal procedimento, Sandel retorna à obra A Theory of Justice e vai buscar no capitulo III, aquilo que Rawls denomina de circunstâncias da justiça. As circunstâncias da justiça são as condições que prevalecem nas sociedades humanas e que tornam a cooperação entre os homens possível e necessária. Devemos imaginar a sociedade como um empreendimento cooperativo, com vistas à obtenção de benefícios mútuos, significando que se encontra essencialmente marcada tanto pelo conflito como por interesses recíprocos. Interesses comuns, na medida em que todos têm a ganhar com a cooperação mútua; o conflito na medida em que, em função dos interesses e de fins distintos, as pessoas passam a ter perspectivas divergentes no que se refere ao modo como os frutos de sua cooperação deverão ser distribuídos. Portanto, para ordenar tais dispositivos em uma sociedade, serão necessários a implementação de princípios os quais desempenham o verdadeiro papel da justiça.

Tendo como referência Hume, Rawls observa que as circunstâncias da justiça são de dois tipos: objetivas e subjetivas. As circunstâncias objetivas da justiça incluem a moderada escassez de recursos, enquanto que, as circunstâncias subjetivas, dizem respeito aos agentes da cooperação, muito embora tenham planos e interesses distintos. Confere então que cada pessoa possui o seu próprio plano de vida, ou a sua própria concepção do bem, que considera a melhor para sua vida. As circunstâncias da justiça são aquelas que ocasionam a virtude da justiça. Sua ausência inviabilizaria a virtude da justiça. Para Rawls, no entanto, as sociedades humanas são caracterizadas pelas circunstâncias da justiça, tornando, por isso, a virtude da justiça necessária . Importante destacar que, para Rawls, as condições que proporcionam a virtude da justiça são condições empíricas. Para ele, os princípios fundamentais da justiça dependem dos fatos naturais sobre a vida dos homens em sociedade e esta dependência é declarada explicitamente na interpretação da posição original (RAWLS, 1971, p. 159). As decisões tomadas pelas partes em tais condições são formuladas à luz de conhecimentos gerais. Os próprios elementos da posição original pressupõem diversos fatos sobre as circunstâncias da vida humana. Este quadro descrito faz Rawls crer que se sua hipótese de partida for verdadeira e adequadamente genérica, tudo o mais estará de acordo, já que sem esses elementos sua teoria seria desprovida de sentido. 
O argumento de Sandel é o de que uma compreensão empirista da posição original está em profundo desacordo com propostas deontológicas . Constata que, se a justiça como virtude dependesse de certas pré-condições empíricas, não estaria claro como é que a sua prioridade poderia afirmar-se incondicionalmente. Sandel não concorda com a afirmação de Rawls quando este ressalta que a sua versão das circunstâncias da justiça segue Hume, pois, conforme Sandel (1982, p. 30), as circunstâncias de Hume não sustentam a prioridade do justo em um sentido deontológico, ao contrário, parte de condições empíricas. Sandel acredita que para apoiar o primado da justiça em um sentido categórico como o postulado por Rawls, seria necessário demonstrar não só que as circunstâncias da justiça prevalecem em todas as sociedades, e sim que isso acontece ao ponto de a virtude da justiça ser sempre mais completa e mais invocada do que qualquer outra virtude. Se assim não for, segundo Sandel, Rawls apenas teria legitimidade para concluir que a justiça é a primeira virtude de certos tipos de sociedades e não para todas as sociedades.

Sandel acredita não ser possível o primado da justiça se realizar empiricamente. Isto é implausível, pois seria improvável ou até mesmo impossível a generalização social por tal argumento, ao menos quando pensado em ser aplicado para todo o espectro das instituições sociais. Talvez esta ambição fique por conta de relações familiares, algumas tribos, aldeias, vilas, ou sindicatos, todas com alguma identidade comum. Mesmo assim, em alguns momentos as circunstâncias da justiça poderiam vir a ser restrita. É improvável, no entanto, que possa vir a realizar-se em grande escala, como por exemplo, nas relações institucionais dos Estados modernos. Sandel refuta a tese de que possa existir em algum momento uma sociedade que tenha como virtude primeira, a primazia da justiça em um sentido empírico. Citando Hume , observa que as convenções humanas estão na origem da justiça. Para Hume, na medida em que aumentássemos a um nível de suficiência a benevolência dos homens e houvesse uma generosidade por parte da natureza, a justiça tornar-se-ia inútil, cedendo lugar a virtudes mais nobres e a bênçãos mais favoráveis a todos. Ocorre que, então, dar importância para as circunstâncias da justiça implica que deveríamos dar a mesma importância para as circunstâncias da benevolência, da fraternidade e de outros afetos, pois são estas circunstâncias que, terapeuticamente, substituem entre os homens as circunstâncias ou mesmo o contexto da justiça.

Para Sandel (1982, p. 34), o progresso da justiça nem sempre significa um progresso moral geral, pois nem sempre esse progresso corresponderia por inteiro a um incremento nas circunstâncias da justiça e também por ser incapaz de compensar devidamente a perda de algumas virtudes mais nobres e certos bens mais valiosos. E, se um incremento da justiça não 
significa um progresso moral incondicional, poderá igualmente demonstrar-se que, em certos casos, a justiça não seria uma virtude, mas sim um vício. Assim, as circunstâncias da justiça são claramente humeanas e não se ajustam ao primado da justiça nem aos temas deontológicos que lhe estão relacionados ao qual Rawls procura defender. Já a concepção deontológica que dá forma à teoria de Rawls, encontra, segundo Sandel, a sua formulação em Kant, cuja epistemologia e ética se dirigiram em grande parte contra a tradição empirista e utilitarista que Hume representa. Rawls recupera de Kant a noção deontológica de justo, sendo que desta noção deriva a força de uma metafisica moral que exclui o apelo às circunstancias humanas contingentes, nas quais se baseia o argumento de Hume sobre a virtude da justiça.

Para Hume, a justiça é o produto de convenções humanas e deriva sua existência da necessidade do seu uso na convivência e na condição social da humanidade. Para Kant, ao contrário, princípios empíricos são inadequados para servirem de fundamento de leis morais (KANT, 1785: p. 109). De acordo com Sandel (1982, p. 36), a perspectiva humeana das circunstâncias da justiça não se adequa ao estatuto privilegiado da justiça e do direito exigidos por Rawls e derivado de Kant. A grande questão que fica, então, é: porque Rawls adota o argumento de Hume em vez de recorrer a Kant. Para Sandel, Kant não ofereceria nenhuma concepção de circunstâncias da justiça com características das sociedades humanas. Fazê-lo seria contradizer o ponto essencial de sua ética nos termos da qual o homem apenas se afirma como ser moral, na medida em que é capaz de se erguer acima das influencias heterônomas e das determinações contingentes da sua condição natural e social, e agir de acordo com um principio dado pela razão prática pura. Para Kant, as circunstâncias da justiça não se situam naquelas condições da sociedade humana que tornam a justiça necessária, mas antes num domínio ideal, abstraído das sociedades humanas, que possibilita a justiça e a moral em geral sendo que este domínio é o reino dos fins. Um domínio que se situa para além do mundo fenomênico o qual o próprio Kant reconhece como apenas um ideal, no qual os seres humanos são admitidos apenas como visitantes fugazes. E agir em tais circunstâncias seria agir como um ser humano não situado.

Rawls precisa ultrapassar certas dificuldades para justificar sua teoria das circunstâncias da justiça e preservar a prioridade do justo. Para tanto, reformula a noção do reino dos fins de modo que possa acomodar uma explicação empírica das circunstâncias da justiça, ao mesmo tempo que elimina as diferenças contingentes entre pessoas que de outro modo nele prevaleceriam. A noção da posição original interpreta o ponto de vista noumênico sobre o significado de ser-se um ser racional livre e igual. Rawls entende que a nossa natureza 
enquanto seres desse tipo, revela-se quando agimos com base nos princípios que escolheríamos quando essa mesma natureza se reflete nas condições que determinam a escolha . Tal como o reino dos fins, a posição original garante a abstração das diferenças pessoais entre seres racionais, bem como do conteúdo das suas finalidades privadas. Ao contrário da versão kantiana, possui a vantagem de se aplicar a seres humanos reais, sujeitos às condições ordinárias das circunstâncias humanas.

Em resposta à Sandel, podemos afirmar que a posição original tem por objetivo alcançar uma forma de estabelecer princípios de justiça capaz de situar para além das influências sociais e naturais contingentes, sem, no entanto, ter de recorrer a um domínio puramente noumênico, um sujeito transcendental totalmente situado para além da experiência. A solução encontrada por Rawls foi a de restringir a descrição das partes na situação original às características que são partilhadas por todos os agentes enquanto seres racionais, livres e iguais. Desenvolve uma teoria da justiça visando a imparcialidade entre as pessoas. Exclui, então, as contingências que diferenciam as pessoas umas das outras. O que é mais importante são os atributos comuns contingentes que pertencem a todos os seres humanos, os quais se transformam em ingredientes essenciais para sua teoria moral. A teoria moral, para Rawls, deve ser livre para operar hipóteses contingentes e fatos gerais como lhe convier, e entre esses fatos encontra-se as circunstâncias da justiça. E são esses fatos que irão viabilizar para que os princípios da justiça produzidos por sua teoria se apliquem a seres humanos do mundo real. É este modelo epistemológico que proporciona a Rawls escapar de seres incorpóreos ou transcendentais situados para além do mundo real.

Rawls, (1971, p. 126), seguindo Hume e até certo ponto Hart, coloca que as circunstâncias da justiça podem ser definidas como as condições normais sob as quais a cooperação é tanto possível quanto necessária. Para ele, embora uma sociedade seja um empreendimento cooperativo para a vantagem mútua, ela é tipicamente marcada por conflitos e ao mesmo tempo por uma identidade de interesses. Enfatiza que existe uma condição de escassez moderada (circunstâncias objetivas da justiça) e o conflito de interesses (circunstâncias subjetivas da justiça). Ou seja, as circunstâncias da justiça se verificam sempre que pessoas apresentam reivindicações conflitantes em relação à divisão das vantagens sociais em condições de escassez moderada. Rawls presume que as pessoas na posição original sabem que as circunstâncias da justiça se verificam e supõe que as partes tentam promover a sua concepção do bem da melhor maneira possível, e que ao fazerem isso elas necessariamente não precisam estar ligadas entre si por vínculos morais prévios. 
Situadas num contexto de aplicação da justiça, as partes vivem num mundo em que há outros sujeitos que, da mesma forma, enfrentam as limitações resultantes da escassez moderada e da existência de exigências concorrentes. De acordo com Rawls (1971, p. 257), a liberdade humana deve ser regulada pelos princípios escolhidos à luz dessas restrições naturais. Desta forma, a teoria da justiça como equidade torna-se uma teoria da justiça humana e entre suas premissas estão os fatos elementares relativos às pessoas e ao seu lugar na natureza. No entanto, esta concepção empírica da posição original reivindicada por Rawls sofre algumas objeções por parte de Sandel. Este, não aceita que aquele recorra à posição original, incluindo como parte de sua descrição uma versão empírica de circunstâncias predominantemente humanas. Conforme Sandel esta combinação seria inadequada e dá lugar à fortes objeções (SANDEL, 1982, p. 40).

Como resposta à Sandel, podemos dizer que a teoria rawlsiana da justiça apesar de ter uma forte concepção deontológica, uma vez que se opõe à abordagem teleológica do utilitarismo, mesmo assim, não se coloca como uma deontologia puramente transcendental. A função do contrato social é extrair os conteúdos dos princípios de justiça de um procedimento equitativo (fair), feito por pessoas racionais, livres e iguais. Neste sentido, Rawls sempre se preocupou em dar uma solução procedimental à questão do justo. Procedimento equitativo em vista de um arranjo justo das instituições básicas para uma sociedade bem-ordenada. "A equidade caracteriza o procedimento de deliberação que deveria conduzir à escolha dos princípios de justiça preconizados por Rawls, ao passo que a justiça designa o conteúdo dos princípios escolhidos" (RICOEUR, 2008, p. 67). Se por um lado a teoria de Rawls nos fornece uma versão contratualista da autonomia kantiana (para Kant, a lei é aquela que a própria liberdade se imporia, se subtraída à inclinação dos nossos desejos e prazeres), por outro, Rawls acrescenta que uma instituição justa seria aquela que uma pluralidade de indivíduos razoáveis e desapegados escolheriam, caso pudessem deliberar numa situação inicial de igualdade. O que Rawls deseja é substituir, na medida do possível, soluções fundacionais por soluções procedimentais quando se refere à questão da justiça.

\section{A posição original e o sujeito moral}

Entender minimamente o que se passa na posição original, ponto de partida de toda a teoria de Rawls, ou mais precisamente da teoria da justiça como equidade, é pressuposto básico para compreender a noção do sujeito moral que tem a pretensão de construir os princípios de justiça. A chave para tudo isto está na compreensão da posição original 
enquanto eixo norteador das partes, quando através de um equilíbrio reflexivo, escolhem os princípios e determinam o modelo de sociedade que pretendem viver. A posição original pode ser analisada a partir de dois ingredientes: de um lado, os nossos melhores juízos de razoabilidade e, por outro, as nossas convicções reflexivas sobre a justiça. Esta é a matéria prima substancial, que, depois de filtrada na posição original, vai nos proporcionar intuitivamente um produto final, ou seja, os dois princípios de justiça assim elaborados por Rawls:

a) Cada pessoa tem um direito igual a um sistema plenamente adequado de liberdades fundamentais que seja compatível com um sistema similar de liberdades para todos.

b) As desigualdades sociais e econômicas devem satisfazer duas condições. A primeira é que devem estar vinculadas a cargos e posições abertos a todos, em condições de igualdade equitativa de oportunidades; a segunda é que devem redundar no maior beneficio possível para os membros menos privilegiados da sociedade (RAWLS, 2011, p. 345).

Se aceitarmos que a descrição da posição original é um reflexo puro de uma determinada circunstância moral humana, incluindo nós próprios, cabe então, a nós pesquisadores, a tarefa de aprofundar o conceito de pessoa envolvida nesse esquema de representação criado por Rawls. Nesse sentido, temos como ponto de partida, algumas considerações que sugerem que a teoria de Rawls tem implícita uma concepção do sujeito moral que, ao mesmo tempo, que produz os princípios de justiça, está sendo influenciado por sua própria imagem e pelos demais integrantes da posição original.

No entender de Sandel (1982, p. 49), seria necessário resolver as perplexidades relativas ao estatuto da posição original, avaliando, então, as reivindicações centrais da concepção rawlsiana como um todo. Enquanto a argumentação principal de Rawls analisa a natureza do sujeito moral como dadas, demonstrando os princípios de justiça a partir da posição original, Sandel, por sua vez, trabalha em sentido contrário. Parte dos princípios da justiça como dados provisoriamente e dirige o seu argumento de volta até o sujeito moral. O argumento que Sandel constrói é o seguinte: assumindo que somos capazes da justiça e, mais precisamente, que somos seres para quem a justiça é primaria, temos que ser criaturas de certa forma relacionadas com as circunstâncias humanas. O que se pode dizer, então, e que tenha de ser verdade, acerca de um sujeito para quem a justiça é a primeira virtude? E como é que a concepção de um agente moral se encontra incorporada na posição original? Para Sandel (1982, p. 49), temos, então, na posição original, um estatuto lógico distinto para descrever que tipo de sujeito moral está ali envolvido. Uma descrição de certo modo necessária, não contingente e anterior a qualquer experiência particular. Um sujeito que se constitui a partir 
da construção mental dando primazia à justiça e defendendo a justiça como a primeira virtude entre todas as coisas.

Reconstruir o raciocínio de Rawls, acerca da natureza do sujeito moral, nos faz situar melhor este debate. Para Rawls, a primeira característica do sujeito capaz de justiça está relacionada à pluralidade em termos numéricos. A justiça não poderia ser aplicada em um mundo no qual houvesse apenas um sujeito, sendo possível somente em uma sociedade de seres múltiplos e distintos entre si. Os princípios da justiça ocupam-se das reivindicações conflitantes que incidem sobre os benefícios adquiridos pela cooperação social e aplicam-se às relações entre pessoas ou grupos de pessoas. A palavra contrato sugere esta pluralidade (RAWLS, 1971, p. 16). Presume-se, então, que para haver justiça, as reivindicações têm de levar em conta todas as pessoas, ou seja, a pluralidade de pessoas passa a ser vista como um pressuposto necessário para a possibilidade da justiça. Rawls insiste na pluralidade essencial do sujeito humano, ao censurar o utilitarismo por levar à sociedade como um todo os princípios da escolha racional específicos do homem individual. No quadro do utilitarismo, muitas pessoas são fundidas em uma só, ocorrendo o perigo da instrumentalização. Levar a sério a pluralidade e o caráter distintivo das pessoas significa defender a liberdade e a independência de pensamento como requer a justiça como equidade.

$\mathrm{Na}$ teoria de Rawls, as características de individuação dos seres humanos são dadas empiricamente, pelo encadeamento lógico das ideias a partir de necessidades e desejos distintos, propósitos e fins que acabam diferenciando os seres humanos em suas particularidades. Cada indivíduo encontra-se em uma forma única no tempo e no espaço. Nasce numa família e sociedade particulares. São as contingências dessas circunstâncias, em conjunto com os interesses, os valores e as aspirações por elas originados, que diferencia as pessoas, fazendo-as serem particulares como são. De acordo com Sandel: A característica fundamental do sujeito moral é a sua pluralidade e, dados os meios de individuação, o número da sua pluralidade corresponde ao número de seres humanos individuados empiricamente no mundo. Tudo isso equivale a dizer que, na perspectiva de Rawls acerca do sujeito moral, cada ser humano individual é um sujeito moral, e cada sujeito moral é um ser humano individual (SANDEL1,1982, p. 52).

Pensamos que Rawls não estaria propondo algo diferente quando afirma que: "a justiça como equidade concede um lugar central para o valor da comunidade [...]" (RAWLS, 1971, p. 264). A ideia que Rawls defende é que os valores sociais, tais como o bem intrínseco das atividades comunitárias institucionais e associativas, são analisados mediante uma concepção de justiça que, nas suas bases teóricas, é individualista. Preocupado com a questão 
da comunidade, Rawls supõe que a sociedade seja um todo orgânico com uma vida própria distinta e superior a todos os seus membros nas relações que estabelecem entre si. Assim, a concepção contratual da posição original é estabelecida em primeiro lugar. É a partir desta concepção, por mais individualista que possa parecer, que temos eventualmente de explicar o valor da comunidade (RAWLS, 1971, p. 265).

Quando Rawls afirma que "partimos da ideia fundamental de sociedade entendida como um sistema equitativo de cooperação" (RAWLS, 1993, p. 34), está querendo nos dizer que quando essa ideia é desenvolvida de modo que especifique uma concepção política de justiça, teremos como consequência uma concepção de pessoa que são capazes de participar da cooperação social e também capazes de assumir responsabilidades por seus fins, de modo que seja possível empenhar-se em realiza-los. Para tanto, contam com os meios que podem razoavelmente esperar obter em troca daquilo com que podem contribuir. Para Rawls, a ideia de responsabilidade pelos próprios fins está implícita na cultura pública política e deve ser realizada em suas práticas. "Uma concepção política de pessoa articula essa ideia e insere em uma ideia de sociedade entendida como um sistema equitativo de cooperação" (RAWLS, 1993, p. 34). As pessoas são concebidas como livres e iguais em virtude de possuírem faculdades da personalidade moral, a saber, a capacidade de ter um senso de justiça e de ter, ao mesmo tempo, uma concepção do bem.

Já para Sandel, assim como para os demais comunitaristas, uma pluralidade de sujeitos e suas experiências reais a partir de uma comunidade, se coloca como anterior às individualidades. Na ética deontológica, ao contrário, o eu é anterior aos objetivos que defende, ou seja, às concepções do bem. "O universo deontológico e o eu independente que se move no seu seio apresentam uma visão libertadora. Livre dos ditames da natureza, bem como das imposições dos papéis sociais, o sujeito deontológico instala-se como um ser soberano" (SANDEL 1982, p. 177). Ao contrário de Sandel, vamos defender que as partes na posição original, não são pessoas totalmente destituídas de propósitos ou incapazes de laços morais. Podem sim, serem pessoas em condições para a escolha de princípios para uma sociedade bem-ordenada, oferecendo primazia para o justo em detrimento do bem. Oferecer uma explicação plausível a esta prioridade é um desafio para Rawls e para aqueles que entendem que sua teoria é coerente com as necessidades de sociedades democráticas contemporâneas. 


\section{Considerações finais}

Dentro desta perspectiva, penso que A Theory of Justice (1971) e sua posterior reformulação em Political Liberalism (1993), correspondem suficientemente às exigências da filosofia política e sua necessidade de servir como alternativa ou modelo às sociedades reais. Existe a possibilidade das pessoas na posição original escaparem de um universo vazio de significados e fazerem parte de um universo composto por sujeitos empíricos, capazes de adotar significados para suas vidas, ou seja, agentes com capacidade de uma escolha racional. Como o eu se distingue de seus fins, isto é, como este agente pode fazer para manter certa neutralidade, proporcionando as condições ideais para a escolha dos princípios (um sujeito destituído de um corpo), um eu numênico distanciado das coisas reais. Por outro lado, será necessário responder de que forma esse eu se encontra ligado às coisas concretas da vida, ou seja, eus empíricos (fenomênico) sendo capazes de escolhas com relação aos seus bens (um corpo radicalmente situado).

Podemos encontrar uma resposta plausível à essa pergunta em Kant. Para Kant, a descoberta de que tenho que me conhecer a mim mesmo, quer como sujeito, quer como objeto da experiência, sugere dois modos diferentes de conceber as leis que governam as minhas ações. Esta descoberta conduz-nos do argumento epistemológico, para um argumento suplementar, prático, em favor da prioridade do sujeito. Enquanto objeto da experiência, eu pertenço ao mundo sensível. Tal como o movimento de todos os objetos, também as minhas ações são determinadas pelas leis da natureza e pelas regularidades de causa e efeito. Em contrapartida, enquanto sujeito da experiência, eu habito o mundo inteligível, ou suprassensível, no qual sou independente das leis da natureza e me apresento como sendo capaz de ser autônomo, isto é, capaz de agir de acordo com uma lei que me dou a mim mesmo.

É, a partir deste segundo ponto, ou seja, habitando o mundo inteligível, que posso considerar-me livre, uma vez que ser livre é não se encontrar sujeito às causas determinantes do mundo sensível, precisamente aquilo que a razão tem sempre que se auto-atribuir (KANT, 1956, p. 120). Do ponto de vista de Kant, se eu fosse um ser totalmente empírico, não teria as condições para atingir a liberdade, na medida em que, todas as ações de minha vontade estariam condicionadas pelo desejo de algum objeto e todas as escolhas seriam heterônomas, governadas pela busca de algum fim. Assim, a minha vontade nunca poderia ser uma causa primeira, mas apenas o efeito de uma causa anterior, instrumento de impulsos ou inclinações. Atingir a verdadeira liberdade significa um afastamento do mundo sensível. Quando 
pensamos em nós mesmos como seres livres, transportamo-nos para o mundo inteligível, como seus membros, e reconhecemos a autonomia da vontade (KANT, 1956, p. 121).

A noção de um sujeito que é anterior à experiência e independente dela, tal como exige a ética deontológica, surge não apenas como sendo possível, mas como indispensável, um pressuposto necessário, possibilitando, então, o autoconhecimento e a liberdade. O desenvolvimento desse raciocínio nos dá o alcance da importância de Kant para a ética deontológica e seu posterior uso por teorias liberais contemporâneas, como é o caso do neocontratualismo rawlsiano. Ficou mais robusta, então, a importância que tem a ética deontológica para o primado da justiça. Na perspectiva kantina, a prioridade da justiça é moral e fundacional. O seu fundamento radica no conceito de um sujeito que é dado antes dos seus fins, considerado indispensável para o nosso conhecimento de nós próprios, enquanto seres capazes de fazer opções livres. As sociedades seriam melhores sob o ponto de vista administrativo, quando governadas por princípios que deixassem de lado uma concepção particular do bem. Qualquer outro ordenamento seria incapaz de respeitar as pessoas enquanto agentes de escolha e as mesmas seriam tratadas como objetos em vez de sujeitos, como meios, em vez de fins em si mesmas.

De nossa parte, fica a noção de que o sujeito moral na posição original é um agente situado holisticamente, ou seja, ao mesmo tempo em que se coloca como um indivíduo isolado psicologicamente, com suas faculdades racionais aptas a fazer escolhas, pode, também, se colocar como que perspectivando um olhar coletivo, levando em consideração o outro. Pessoas assim são movidas por um interesse moral coletivo, pela capacidade de serem equitativas, interesse esse que se faz específico na formulação dos princípios que levam em conta o pressuposto de que todos devem ter, no ponto de partida, direito a uma igual parcela dos bens primários produzidos em uma sociedade bem-ordenada. Este enfim, é o modelo de sociedade preconizado por Rawls em sua teoria da justiça como equidade.

\section{Referências}

RAWLS, John. A Theory of Justice. Cambridge: Harvard University Press, 1971.

Uma teoria da justiça. São Paulo: Martins Fontes, 2002 a.

Political Liberalism. New York: Columbia University Press, 1993.

1999.

Collected Papers, ed. Samuel Freeman. Cambridge. MA: Harvard University Press, 
Lectures on the History of Moral Philosophy. Cambridge. MA: Harvard University Press, 2000.

O liberalismo político. São Paulo: Martins Fontes, 2011.

Outline of a decision procedure of ethics. Philosophical Review, 60, p. 177-197. 1951

a.

Justiça e democracia. São Paulo: Martins Fontes, 2002 b.

Justice as Fairness: A Restatement, ed. Erin Kelly. Cambridge, MA: Harvard University Press. Third printing, 2003.

O direito dos povos. São Paulo: Martins Fontes, 2004.

Historia da filosofia moral. São Paulo: Martins Fontes, 2005.

Teoria de la justicia. Madrid: Fondo de Cultura Econômica, 1978.

The Independence of moral theory. Proceedings and Addresses of the American Philosophical Association, 48, 5-22, 1975.

The Law of Peoples. Cambridge. MA: Harvard University Press, 2001.

KANT, Immanuel. Crítica da razão prática. São Paulo: Martins Fontes, 2002.

The Critique of Pure Reason. London: Encyclopedia Britannica, v. 42. 1952.

The Critique of Judgement. London: Encyclopedia Britannica, v. 42. 1952.

Groundwork of the Metaphysics of Morals, tradução de H.J. Paton. New York, 1956.

Fundamentação da metafísica dos costumes. São Paulo: Abril Cultural, 1989.

NOZICK, Robert. Anarquia, Estado e Utopia. Rio de Janeiro: Jorge Zahar, 1994.

Anarchy, State and Utopia. New York: Basic Books, 1974.

POGGE, Thomas. John Rawls: his life and theory of justice. New York: Oxford University Press, 2007.

RICOEUR, Paul. O justo 1: a justiça como regra moral e como instituição. São Paulo: Editora Martins Fontes, 2008.

SANDEL, Michael J. Justiça - O que é fazer a coisa certa. Rio de Janeiro: Civilização Brasileira, 2012.

Liberalism and the Limits of Justice. Cambridge: Cambridge University Press, 1982. 
O que o dinheiro não compra: os limites morais do mercado. Rio de Janeiro: Civilização Brasileira, 2012.

SILVEIRA, Denis Coitinho. Ensaios sobre ética: complementariedade entre uma ética dos princípios e das virtudes. Pelotas: Editora e Gráfica Universitária, 2008.

TAYLOR, Charles. As Fontes do Self: a construção da identidade moderna. São Paulo: Edições Loyola, 1997.

Atomism In: AVINERI, Shlomo e DE-SHALIT Avner. Communitarianism and individualism. New York: Oxford University Press, 1992, p. 29-50.

Philosophical Arguments. Harvard University Press, 1995.

Argumentos filosóficos. São Paulo: Edições Loyola, 2000.

A ética da autenticidade. São Paulo: Realizações Editora, 2011.

\section{Sobre o autor:}

Ubiratan Trindade é Doutorando PPGF pela Unisinos. 